\title{
Crowd logistics: an opportunity for more sustainable urban freight transport?
}

\author{
Heleen Buldeo Rai $^{1}$ • Sara Verlinde ${ }^{1} \cdot$ Jan Merckx $^{2} \cdot$ Cathy Macharis $^{1}$
}

Received: 27 October 2016 / Accepted: 7 July 2017 /Published online: 22 July 2017

(C) The Author(s) 2017. This article is an open access publication

\begin{abstract}
Purpose Passenger car occupancy has been falling for years. Partly empty vehicles on our road networks decrease passenger transport sustainability but also contain an opportunity for freight transport. Within Crowd logistics (CL), delivery operations are carried out by using passengers' excess capacity on journeys that are already taking place, resulting in economic, social and environmental benefits. Existing CL initiatives show, however, that there are important differences between concepts in terms of sustainability. The research aims to develop a suitable and comprehensive definition for CL and identify which factors determine the sustainability potential of CL.

Methods We systematically analysed a set of 42 papers and interviewed 11 logistics practitioners in order to capture the state of practice.

Results Following the literature and interviews, we firstly define $\mathrm{CL}$ as 'an information connectivity enabled marketplace concept that matches supply and demand for logistics services with an undefined and external crowd that has free capacity with regards to time and/or space, participates on a voluntary basis and is compensated accordingly'. Secondly, we identify a set of 18 characteristics that can describe the variety of CL concepts. Thirdly, we indicate whether the identified characteristics affect the economy, society and/or environment. The research shows that all characteristics influence economic
\end{abstract}

This article is part of Topical Collection on Accommodating urban freight in city planning

Heleen Buldeo Rai

heleen.buldeo.rai@vub.be

1 Vrije Universiteit Brussel (VUB) - MOBI, Pleinlaan 2, 1050 Brussels, Belgium

2 VIL, Koninklijkelaan 76, 2600 Antwerp, Belgium sustainability while 11 characteristics also affect social and/ or environmental sustainability.

Conclusions Our research helps local policy-makers to adapt laws and regulations to the sharing economy developments and provides insight for businesses which CL concept fits their company's corporate social responsibility strategy.

Keywords Crowd logistics · Crowdshipping · Sustainability · Urban freight transport · City logistics

\section{Introduction}

The distribution of goods in urban areas is a point of departure in many research papers, in which both its essential character and the many sustainability issues it raises, are acknowledged. Essential, because most goods are not consumed where they are produced, which is particularly true for cities, leading to the necessity to transport large amounts of goods and waste into and out of the city [33]. Urban freight transport (UFT) contributes to wealth generating activities and the competitiveness of industry [1], but it also generates negative social and environmental impacts. These impacts include, but are not limited to, fossil fuel consumption, greenhouse gas emissions, air pollution, noise, road safety and traffic congestion. Moreover, those performing freight transport operations experience problems that relate to traffic flows, transport policy, loading/unloading and customer service, which are considered negative economic impacts [37]. In order to address these issues, many innovative solutions have been introduced. Most proposals concentrate on enhancing either passenger or freight flows. Given the average passenger car occupancy rate of 1.45, driver included [49], a significant part of the available transport capacities is not exploited [2]. The growing interest in shared passenger and freight transportation practices [31] 
indicates that an important opportunity could be in combining both. Crowd logistics (CL) - alternatively termed crowdshipping, crowdsourced delivery, cargohitching or collaborative logistics - is presented as a promising concept as it encourages passengers to use their spare carrying capacity on cars, bikes, buses and planes to carry parcels for other people [38]. CL uses the excess capacity on premeditated trips that already take place to make deliveries [3], leading to maximisation of logistics efficiency and reduction of emissions and traffic [2-9, 23-25, 31, 38, 41].

$\mathrm{CL}$ relates to the idea of the physical internet, as well as to the global sharing economy trend. The physical internet is a concept for freight transportation and logistics, aiming to improve efficiency and sustainability of the way physical objects are moved, stored, realised, supplied and used all across the world by applying concepts from internet data transfer to realworld shipping processes [8]. The idea is to encapsulate physical objects in modular packets and containers of which the header contains all information required for identifying the packet. These packets and containers are then routed as efficiently as possible so that it absorbs spare capacity in transport systems, ensuring that they get to their destination in time, regardless of the route followed [38]. CL relates to physical internet because technology enables passengers to use the capacity in their vehicle more efficiently, by carrying parcels for others. Sharing your vehicle with (freight volume of) others makes CL also part of a larger trend of sharing, termed the collaborative or sharing economy, which is a fast-growing sector disrupting mainstream industries $[3,10]$. In the sharing economy, physical assets become services that are redistributed, shared and reused more easily and inexpensively than ever before, thanks to technological advancements [3, 11]. Vaughan and Daverio [42] detect a thriving start-up scene for sharing initiatives across Europe and estimate that at least 275 platforms have been founded to date. A survey instructed by the European Commission shows that half of the respondents $(52 \%)$ have heard of such sharing economy platforms and around two in ten respondents say that they have used them (17\%). The most likely users are younger and highly educated respondents who live in urban areas [43]. The sharing economy affects a variety of sectors, including mobility and transportation, to which CL belongs.

To date, limited scientific research has been done on the potential economic, social and environmental benefits of sharing economy activity in general and $\mathrm{CL}$ in particular. Primarily practitioners have been showing interest in CL, resulting in a growing number of start-ups and platforms. Increasingly, concepts are introduced that deviate from the initial idea, to a small extent by allowing considerable detours from the planned journey and, to a larger extent, by depending on dedicated trips. UberRush and Postmates, for example, offer on-demand deliveries. Their couriers make themselves available for a self-chosen period to use their own vehicle to carry out dedicated deliveries [50-52]. This way of working raises the question which types of CL concepts have the ability of increasing urban sustainability of both passenger and freight transport.

To address this question, we combined desk and field research. First, we systematically reviewed the available literature to formulate a comprehensive definition of CL. Second, we defined a set of 18 criteria that characterise the variety of CL concepts. Theoretical insights were verified with 11 semistructured interviews with practitioners that expressed an interest in using the crowd in their logistics activities. Third, we used the same body of information to evaluate whether these 18 characteristics affect economy, society and environment.

This paper covers a literature discussion in the second section, in which the CL concept is introduced and fit in the 4 A's of sustainable city distribution framework that classifies innovative city distribution solutions [12]. The third section clarifies the methodological approach of the research while the fourth section elaborates on research findings. The fifth section discusses these findings and explains final conclusions.

\section{Literature}

CL originates from the term crowdsourcing, which covers both the word 'crowd' or a mass of people and 'outsourcing' or the shift of processes, functions and duties to third parties [24]. In the transition towards sustainable UFT, CL has the capacity to contribute. Sustainable development is most commonly defined as 'meeting the needs of the present without compromising the ability of future generations to meet their own needs' [44]. With this, the joint harmonisation of three issues is implied: economic growth, social equality and protection of environmental resources [13]. This could also be referred to as the triple-P or triple bottom line of sustainability (People, Profit, Planet) [34]. For the UFT system to reach comprehensive sustainable development, necessary requirements are economic development and vitality, social wellbeing and environmental preservation and regeneration [35].

In economic terms, the success of many sharing economy initiatives indicates the substantial efficiency gains that can be realised [45]. With regards to logistics, CL provides consumers access to a more extensive range of products [14] and superior delivery service by being faster [3, 14, 31], more flexible [2, 24, 25], more convenient [23], more personal [14, 23], traceable in real-time [15] and better priced [2, 3, 23]. Businesses benefit from CL since it has the potential to reach a large area [2,9], relies upon a flexible workforce [26] and requires only an asset-light infrastructure that makes investments in vehicle fleet, employees and maintenance redundant $[2,3,14,16,25,26]$. The crowd is motivated by additional earning opportunities that are flexible, personalised and adaptable to their lifestyle $[2,23,25]$. From a social point of view, 
the local character of CL is stressed, enabling the crowd to have personal contact with their neighbourhood and empowering communities $[2,9,26]$. The most significant contributions of $\mathrm{CL}$ are, however, envisioned from an environmental perspective. By utilising existing transportation flows, CL encourages consolidation [10], leads to more efficient vehicle loads and routes [2,7] and reduces traffic, congestion and air polluting emissions [2-8, 23, 25, 31, 41].

Macharis and Kin [12] propose a classification called the 4 A's of sustainable city distribution that clusters innovative concepts based on their primary intention: Awareness, Avoidance, Act and shift and Anticipation of new technologies. It could be argued that CL complies with all A's. First, by involving a crowd of randomly united citizens, awareness is created of the challenges that last mile transportation and home delivery impose on the city. E-commerce and omnichannel retail, which integrates online and offline sales channels, stimulate a rising amount of individual parcels and delivery vans [17]. At the same time, altered mobility, demographic change and increasing employment reduce the possibility to successfully receive deliveries in person [28]. This 'online shopping paradox' has substantial consequences regarding environment and quality of life, yet it is unlikely that consumers take these into account when placing orders. CL enables consumers to observe the large quantity of parcels that circulates in the neighbourhood, city or region and the spatial opportunities of commuters that move between home and business every day.

Second, by encouraging citizens to make use of the free capacity on a trip that was intended to be made either way, redundant vehicle kilometres of polluting vans can be avoided. Moreover, as citizens are more flexible and interconnected than traditional logistics service providers (LSPs), the number of failed deliveries can be reduced. In addition, integrating the crowd with other initiatives such as small load containers and pick-own-parcel stations potentially provides sustainability advantages in the future $[4,27]$.

Third, as citizens are invited to carry a chosen amount of parcels on a chosen time and trajectory, the possibilities for shifting to alternative modes increase considerably. The crowd can opt to deliver a parcel on their daily commute by public transportation or to pick up their neighbours' parcels and carry out the deliveries by bike or on foot.

Fourth, CL is an evident example of new technologies anticipation and digitalisation, as it is primarily based on exploiting the potential offered by mobile apps, geolocalisation, communication and navigation tools [14, 23]. Crainic and Montreuil [8] discuss CL as an example of hyperconnected city logistics, in which the physical internet concept is applied to urban environments, resulting in interconnected people mobility and freight logistics in the city.

The CL concept exploits a new spirit of collaboration and commercialises social networks in a way that can be beneficial from an economic, social and environmental point of view
[46]. However, as leading enterprises (retailers and LSPs) are embracing this paradigm shift in the distribution of work, by outsourcing to the crowd in the cloud [18], much of the thinking and discussion about CL has developed from the practitioner's side [26]. Examples of such initiatives include Myways, a terminated pilot project of DHL that was launched in Sweden [53], bringr, an experiment by the Belgian postal operation bpost [54] and efforts of retailer Walmart in the USA, at first with in-store customers that served as crowd, later on in cooperation with CL start-ups Lyft, Deliv and UberRUSH [55]. The latter example demonstrates the importance for businesses starting up in the increasingly competitive delivery service industry to collaborate with traditional or mature companies. The collaboration between fashion e-retailer Zalando and CL initiative Trunkrs for last-mile deliveries in Amsterdam possibly fosters advantages for Trunkrs, such as brand awareness, consumer trust and user generation [56].

Together with the rise of CL initiatives, the variety of business models that are applied has grown considerably. Some concepts are dependent on a base of regular and flexible 'crowd workers', others allow (long) detours or encourage dedicated trips to deliver parcels. This causes discussion about the true capacities of CL to enhance urban sustainability. The research therefore aims to identify the characteristics that describe the various CL concepts and evaluate how these characteristics affect the economic, social and environmental sustainability of the concept. In order to do this, a clear definition of CL is warranted. However, no attempts have been made so far. The only exception being the definition by Mehmann et al. [24], who claim that ' $C L$ designates the outsourcing of logistics services to a mass of actors, whereby the coordination is supported by a technical infrastructure. The aim of CL is to achieve economic benefits for all stake- and shareholders.' Despite the variety of concepts and utilitarian approaches that exist within the realm of CL, we argue that the objective of economic benefits is too narrow. Therefore, the research aims to develop a suitable and comprehensive definition of CL that captures current and future state of practice.

\section{Methodology}

The methodological approach includes both desk and field research by means of a systematic literature review (SLR) and semi-structured interviews. A SLR is a systematic, explicit and reproducible method for identifying, evaluating and synthesising the existing body of completed and recorded work produced by researchers, scholars, and practitioners [36]. By reviewing the available scientific literature on CL, we captured the knowledge that is available to date. We used a spreadsheet file to compose a comprehensive analysis of the $\mathrm{CL}$ descriptions, defining characteristics, involved parties and their activities, strengths and weaknesses. Additionally, the 
SLR took stock of all CL examples mentioned, which were examined in an explorative way. Literature was found using Google Scholar, which as an open and extensive database was fit best for researching this novel topic. Furthermore, the online databases of ScienceDirect, Web of Science and Taylor \& Francis were checked but did not result in additional material. Several keywords were used and are listed in Table 1.

The search yielded 139 publications, of which 23 publications were found twice or more. An additional total of 55 publications were found unqualified, as 28 were identified as student thesis; 25 were unrelated to the subject or only mentioned $\mathrm{CL}$ in the list of references and 2 were excluded due to language barriers (Swedish and Finnish). Finally, 8 publications could not be accessed (Table 2). The literature search thus provided an input of 42 qualified and accessible papers.

Because of the novelty of the topic, the search strategy included journal output but also other types of scientific publications, including conference papers (13), working papers (3), book chapters (3), project reports (1), white papers (1) and semi-scientific magazine articles (2). The 19 journal publications cover a diversity of journals including Transportation Science, International Journal of Web Information Systems, Journal of Cleaner Production and International Journal of Sustainable Transportation. All publications were written in English except for three (French and German). As far as region is concerned, $\mathrm{CL}$ is researched all over the globe. Although most research is based in Europe (20), other frequently found regions include Canada (4), Asia (4) and the USA (4). Four publications are located elsewhere (Australia, South-America and WestAfrica). The remaining publications (6) could not be geographically classified.

The CL phenomenon is relatively new and understudied. As the systematic literature review indicated that sustainability implications are highly dependent on a number of parameters, we identified a need to involve logistics practitioners. Findings of the SLR provided input for the topic list that guided the semi-structured interviews and were also used as probes for follow-up questions. The findings were, however, not shared with the respondents until all interviews were carried out. Afterwards, the results of both literature and interviews were presented in a general meeting. During the interviews, open questions explored a qualified definition for CL, an analysis of Strengths, Weaknesses, Opportunities and Threats (SWOT) of CL from their company's perspective,

Table 1 Literature selection keywords and findings (2 February 2017)

\begin{tabular}{llll}
\hline Keywords & Total & Keywords & Total \\
\hline Crowdshipping & 37 & "Crowdsourced deliveries" & 10 \\
"Crowd logistics" & 34 & "Crowdsourcing delivery" & 18 \\
"Crowdsourced delivery" & 33 & "Crowdsourcing deliveries" & 7 \\
$\mathbf{1 3 9}$ & & & \\
\hline
\end{tabular}

Table 2 Literature selection exclusion criteria (2 February 2017)

\begin{tabular}{llll}
\hline Exclusion criterion & Total & Exclusion criterion & Total \\
\hline Double publication & 23 & Unrelated subject & 25 \\
Student thesis & 28 & Inaccessible publication & 8 \\
Language barriers & 2 & & \\
$\mathbf{8 6}$ & & & \\
\hline
\end{tabular}

interesting CL concepts, current and future CL activities and finally their opinions on the sustainability implications of CL in general and the importance attached to sustainability issues when developing their own CL concept. In this way, we verified theoretical insights with the state of practice.

In total, 11 semi-structured interviews were conducted with practitioners: 8 LSPs, 1 shipper and 2 retailers. The practitioners were selected because of their stated interest in integrating or developing crowd-based activities in their logistics operations. Both size and geographical reach of practitioners differs considerably, from family-owned local business to multinational, but all have a headquarters within Flanders and Brussels capital region, Belgium.

In general terms, the interviewed practitioners agreed on the concept definition of CL. More disagreement was observed concerning the underlying motivations for getting involved in $\mathrm{CL}$ : while shipper and retailers were interested in the added value and service it potentially offers, LSPs were motivated by existential considerations and the possibly disruptive character of CL developments. Practitioners' interest also differed with regards to specific CL concepts, which was in line with core activities and company's mission and vision. For example, a company with strong environmental efforts envisioned a CL concept in line with these commitments, as opposed to another company in which sustainability is also in its daily activities of minor importance.

Compliant with the CL concept, we created an adapted stakeholder-framework consisting of receivers that receive the goods, commissioners that send the goods, LSPs that execute transportation in the traditional way, platform providers that match all parties and, finally, the crowd. Throughout the interviews, we identified 4 LSPs expressing the ambition to additionally become a platform provider, 2 platform providers that already host a logistics platform but aim to include the crowd and 2 LSPs and 3 commissioners that wish to use the crowd without hosting a platform (see Appendix for a list of interviewees).

\section{Findings}

\subsection{Definition}

Following the SLR and the semi-structured interviews, we identified seven elements that are crucial to CL, in an attempt to compose a comprehensive definition: 
- Technological infrastructure

- Free capacity

- Crowd network

- Undefined character

- External to the company

- Compensation

- Voluntary

First, technological infrastructure by means of an accessible platform is critical in CL, in order to coordinate demand and supply for logistics services. This platform can be accessed in a multitude of ways, such as mobile phone or web browser [24], and provides the opportunity to engage a broad spectrum of workers [28]. Critical for future success of CL is the optimisation technology that supports and analyses [41]. Practitioners highlighted that information connectivity is the main enabling factor and termed the technological infrastructure element as 'online marketplace' or 'communication platform', required to connect flows of goods, information and finances.

Second, CL implies the use of free capacity. Delivery operations are made by using the excess capacity on journeys that are already taking place [3]. According to Mckinnon and Bilski [38], harnessing this spare capacity enables to achieve economic and environmental benefits. The interviews, however, nuanced this literature finding by adding that free capacity can also refer to time, instead of volume. Many CL concepts in which practitioners expressed concrete interest in, consider the crowd as a database of people willing to execute logistics tasks in their free time.

Third element refers to the network. Botsman [14] proposed a 'network of drivers', but this is contradicted both by existing CL concepts and by the interviews. For example, a number of CL concepts can be used for logistics services that cover more activities than merely transportation. Trunkrs, a Dutch initiative, appoints neighbours that offer small-scale warehousing services, by collecting deliveries and returns [57]. Moreover, Instacart, a USbased on-demand grocery service, provides store picking in addition to home delivery [58]. An interviewed practitioner added that $\mathrm{CL}$ enables commuters that use public transportation to carry parcels for others, thus without them needing to be drivers.

Fourth, the undefined character of the crowd, as proposed by different authors $[2,6,16]$. The practitioners acknowledged this as an essential element of CL but indicated that the unknown crowd identity represents a substantial source of stress. Although the platform registers and tracks the crowd, quality and service are more difficult to monitor and cannot be guaranteed.

Fifth, when making use of the crowd, there is no formal hiring process [39]. The crowd does not become an employee but remains external to the company [41]. For some of the practitioners, this element proved to be motivating as the employer is released from a number of commitments and obligations. Others expressed concerns about excessive forms of flexibility in labour, unfavourable for the labourer.
Sixth, a number of authors state that the crowd receives a micro-payment based incentive or minimal fee in return for their logistics services [11, 15, 23, 29, 41]. While some of the practitioners agreed, the objection against the 'minimal' character of the remuneration was recurring. Framed within the convenience economy trend, most practitioners envisioned to engage the crowd in order to improve overall service levels. Thus, if the crowd provides faster delivery, more personal service, flexibility, larger reach or cost-efficiency, it should be paid accordingly. Thus, it can be concluded that an adequate compensation is an essential element of CL.

Seventh and final, the engagement of the crowd is voluntary, meaning that people self-select logistics services they wish to fulfil $[2,20,23]$. Throughout the interviews, some discussion about this element came to light. While for some practitioners, CL implies irregular activities, others consider labour on both a regular and irregular basis as fitting. Nevertheless, given the absence of a fixed contract, the voluntary character of the crowd remains a fundamental element.

Although discussion about the CL concept seems inevitable, we define CL as 'an information connectivity enabled marketplace concept that matches supply and demand for logistics services with an undefined and external crowd that has free capacity with regards to time and/or space, participates on a voluntary basis and is compensated accordingly'.

\subsection{Characteristics}

In order to characterise the broad variety of CL concepts, we identified 18 characteristics and categorised these in accordance with the involved CL stakeholders that they relate to. An overview of these characteristics is presented in Table 3, followed by a description of each characteristic.

\subsubsection{Receiver and commissioner}

Although often perceived as a peer-to-peer service concept [2, 9, 14], CL can be initiated and destined by both business and consumer. One of the interviewed practitioners preferred to use the term 'human-to-human', thereby indicating that identity of receiver and commissioner is of little relevance. Nonetheless, the business (B) or consumer $(C)$ distinction is an important element in the business model.

\subsubsection{Logistics service provider}

CL has the crowd in its core, but the mass of individuals is often complemented with professional LSPs. As a matter of fact, the most promising CL start-ups are relying primarily on third party involvement: professional couriers who are dedicated to delivery, not only occasional travellers [21, 23]. As the CL concept is highly dependent on a large number of people with a generous amount of flexibility [11], activating 
Table 3 Crowd logistics characteristics

\begin{tabular}{|c|c|c|c|c|c|}
\hline & Receiver & Commissioner & LSP & Platform provider & Crowd \\
\hline Criteria & $\mathrm{B}^{\mathrm{a}}$ or $\mathrm{C}^{\mathrm{b}}$ & $\mathrm{B}^{\mathrm{a}}$ or $\mathrm{C}^{\mathrm{b}}$ & Third party involvement & $\begin{array}{l}\text { Revenue model } \\
\text { Role } \\
\text { Strategy } \\
\text { Logistics task management } \\
\text { Location dependence } \\
\text { Transparency } \\
\text { Trust generating mechanism } \\
\text { Cooperation } \\
\text { Marketing } \\
\text { Geographical scale }\end{array}$ & $\begin{array}{l}\text { Character } \\
\text { Transport } \\
\text { Incentive } \\
\text { Motivation } \\
\text { Modal choice }\end{array}$ \\
\hline
\end{tabular}

${ }^{\mathrm{a}}$ Business

${ }^{\mathrm{b}}$ Consumer

professional third parties is a way to ensure timely completing of tasks [16]. The interviews acknowledged this strategy.

\subsubsection{Platform provider}

A number of characteristics allow to typify the platform provider. Rougès and Montreuil [23] list eight revenue models: fixed price, resale margin, financial or matching fee, negotiated price, membership, reward, barter and discount. Designing a qualified model or combination of models is crucial. By applying gametheory, Kung and Zhong [32] investigate three pricing strategies and conclude that adopting a membership-based model would be more profitable than the others. For many of the interviewed practitioners, the desirable revenue model was still unclear but has to be in line with the other CL characteristics. A matching fee was found appropriate for a platform that aims to connect private individuals for the transportation of personal, non-parcel sized goods. A fixed price for every performed task was suggested for a CL concept relaying primarily on professional drivers. For commissioners facilitating the crowd to collect their neighbours' order, a percentage of a negotiated price between the parties was found suitable.

The role of the platform is mostly categorised as marketplace. However, depending on other activities the platform provider offers, this role can alter or expand. Carbone et al. [26] define the difference between platforms in which logistics services are the purpose on the one hand, and are supporting collaboration on the other hand.

Closely linked to platform role is strategy. Although initially framed within the sharing economy concept [24], with social relationships at its heart [26], the expansion of more utilitarian approaches urged for a broader definition. The typology of Rougès and Montreuil [23] includes three distinctions: efficiency versus human, trust versus control and business versus community. Cohen and Muñoz [10] elaborate on an orientation which is public or private and additionally introduce a hybrid approach. Combining aspects of both, this CL characterisation framework implements a businesscommunity axis with hybrid strategies in between. The practitioners interviewed referred in most cases to businessoriented strategies, putting emphasis on additional or improved services that could be offered to their customers and cost-efficiency motivations. Two interviewees explicitly expressed interest in a community-inspired concept.

The logistics task management of the platform can be organised in an centralised or decentralised way [26]. While a decentralised platform plays only an informative role, a centralised management handles the flows and pushes information to the crowd. Chen et al. [29] make the difference between large-scale task coordination, where the platform proactively recommends tasks to the crowd in a coordinated way, and predictive crowd-tasking, where the recommendation of tasks is not solely based on current location.

Related to this is the trajectory-dependency condition. A platform can be programmed to match supply and demand based on explicitly inputted trajectories or can be independent from existing trajectories by allowing random matches. Most concepts introduced by the interviewed practitioners require a semi-professional and regularly active crowd and consequently manage logistics tasks in a centralised and trajectoryindependent way. Other concepts use the capacity of trips that are already taking place but allow considerable flexibility with regards to detours.

Transparency and trust generating mechanisms both aim to decrease the safety risks that are inherently related to the $\mathrm{CL}$ concept. According to literature and interviews, insecurities such as increased risk of theft, loss and damage [25], privacy concerns [2] and vulnerability to criminal activity [25] form major barriers. Also with standard delivery, a certain amount of loss and theft is assumed [9]. In order to 
respond to these insecurities and reassure users, a number of mechanisms can be introduced: rigorous selection process, feedback system, personal web pages or spaces, secure messaging system, secure online payment system and insurance [23]. All were endorsed by the semi-structured interviews, although there was considerable interest in more advanced control-providing mechanisms such as pre-screening of the crowd. Nevertheless, in a pilot project in Finland, in which crowdsourcing for library deliveries was tested by using the platform PiggyBaggy, no failures, lost or damaged goods were encountered [7].

Cooperation within a CL concept refers particularly to partnerships with IT specialists, investors and most prominently, retailers. According to Mehmann et al. [24], a CL concept can be categorised 'effective' when five to ten retail partnerships are achieved. For the pioneering Bringbee concept from Switzerland, an insufficient amount of partners caused them to cease activities [59]. Research states that for 'click-and-mortar businesses' that have both a physical and online shop, $\mathrm{CL}$ is an effective way to compete with pure eplayers. They can employ their often strategically located physical stores as 'warehouse', from which the crowd can realise fast one-hour or same-day deliveries [14, 23]. Specifically for independent, local businesses the crowd can provide affordable delivery solutions $[5,40]$ and enable them to widen their markets [23].

A critical mass of platform-users needs to be acquired by means of effective marketing [23]. According to Taylor [28], the long-term success of CL concepts depends on attracting a sufficiently large number of participants. Internet advertising, social media and bonus programs are mentioned [24]. For the practitioners interviewed, a vision on user-acquisition strategies was still unclear. Nevertheless, for the companies that took environmental and social gains into account, the CL concept itself was seen as an image-improving tool.

Geographical scale concerns the market size and covered distances of the CL concept. The distinction can be made between intra-urban, inter-urban and global scale on the one hand [23] and regional, national, international and worldwide scale on the other hand [2]. Literature generally limits the CL concept to city distribution and last mile logistics $[2,3,6,22$, $24,25,30]$. The interviewed practitioners, however, expressed interest in concepts in which city logistics is just one component and even concepts that exclude the last mile.

\subsubsection{Crowd}

To describe the crowd, we identified five characteristics. Character of the crowd can be either private or self- employed. Due to the variety of distinctions, subdividing the crowd is complex but important, as it raises legal issues. Established lines between consumer and provider, employee and self-employed, professional and nonprofessional provision of services are blurred [47]. Botsman [14] divides the crowd in three categories: subcontractors, professional drivers and casual drivers. Subcontractors work for mainstream brands such as DHL, professional drivers are employed by courier companies but dispose of free capacity and casual drivers comprise university students, retirees and freelancers. In the pilot project in Finland, the crowd consisted of both local inhabitants and pizza-deliverers [7]. Chen et al. [6] investigated the possibilities of using taxis and the Dutch initiative Sjipit only accepts independents on its platform, irrespective of their professional activities [60].

Until recently, Belgian law was indistinct about the possibilities of remunerating private individuals in return for services. Now, a tax system modification enables individuals to earn up to $€ 5000$ per year with digital platforms, without the commitments of self-employment that include a value added tax number and social contributions [61]. This modification is in line with the 'European agenda for the collaborative economy'. With this document, the European Commission provides legal guidance and policy orientation for the balanced and sustainable development of the sharing economy, in response to the variation of regulatory and tax policies across the EU member states. For the European Commission, setting thresholds under which an economic activity would be considered a non-professional peer-to-peer activity is a suitable way forward. Because of the blurring lines between consumers and businesses, it becomes less clear who represents the 'weaker party'. Hence, uncertainty is created as to applicable rights and the required level of social protection [47]. In conclusion, although engaging private individuals in CL initiatives is permitted, the character distinction remains relevant.

Closely linked to the crowd character is transport fulfilment, being either dedicated or intended. A number of authors $[3,7,9,11,14,23,41]$ explicitly mention intended fulfilment by referring to pre-existing travel routines [9], commuting trips [23] or delivery locations near the own destination [11]. Without the condition of using the existing vehicle flows, unnecessary travels might be induced [31]. In the Finnish pilot project, Paloheimo et al. [7] found that rebound effects, such as drivers traveling longer distances motivated by monetary compensation, can reduce environmental improvement. In accordance with the 'free capacity of time' argument, also the interviewed practitioners confirmed that $\mathrm{CL}$ does not have 
to imply existing travel and expressed interest in dedicated transportation.

Crowd compensation depends on the incentives offered, which can be monetary or non-monetary. As the identity of the crowd is not stable over time, incentivising is challenging [16]. Compensation schemes based on the 'cost-to-serve' of a customer may be most appropriate [11]. Other value propositions could be added such as health benefits when soft modes, bikes for instance, are encouraged or because of improved local air quality. In the pilot project in Finland, novelty proved to be an important factor [7]. Furthermore, Mladenow et al. [2] state that many crowdsourcing projects are successful without any monetary compensation at all. All interviewed practitioners agreed on appropriate monetary remuneration of the crowd depending on the service executed. Some interviewees suggested additional non-monetary incentives, such as events to strengthen the crowd's community feeling. This is in line with the suggestion by Mckinnon [46] to offer the crowd non-pecuniary factors to build critical mass. Although the crowd consists of external and uncontracted individuals, the learning curve argument was mentioned. This indicates the contradiction that logistics practitioners experience between a flexible database of crowd workers that can be employed depending on the exact need and a regular workforce that masters a specific logistics task or delivery route by repeating it. Both ways of task allocation can lead to costefficiency but they are difficult to combine.

Another incentive-related question was raised concerning payment per service or payment per hour. Also here, the tax system modification plays an important role. Now it is possible to compensate private individuals per service whilst before, an hour-based contract was required. Nevertheless, some practitioners who regard the crowd as a flexible workforce, prefer to maintain the currently used compensation system for employees and simply transfer it to the crowd.

Closely related to incentivising the crowd and the concept strategy, is the crowd's motivation. In accordance with the business-community axis, the crowd can have a clear financial stimulus or can be encouraged by sustainability and community matters, including everything in between. As stated by Paloheimo et al. [7], addressing motives such as schedule fit and ease of use are crucial.

The last crowd characterising element is the transport mode that is chosen. In the Finnish CL pilot, a vital factor of the achieved reduction in resource use and carbon emissions was the fact that most trips were done by bike [7]. The Spanish CL concept, Koiki, facilitates a green delivery service by appointing 'Koikis' or individuals that are engaged to receive all the neighbourhood's parcels and distribute them by foot or

Table 4 Crowd logistics sustainability implications

\begin{tabular}{|c|c|c|c|c|}
\hline \multirow[t]{2}{*}{ Stakeholder } & \multirow[t]{2}{*}{ Criterion } & \multicolumn{3}{|c|}{ Sustainability } \\
\hline & & Economic & Social & Environmental \\
\hline Receiver & $\mathrm{B}$ or $\mathrm{C}$ & & & \\
\hline Commissioner & $\mathrm{B}$ or $\mathrm{C}$ & & & \\
\hline LSP & $\begin{array}{l}\text { Third party } \\
\text { involvement }\end{array}$ & & & \\
\hline \multirow[t]{10}{*}{ Platform provider } & Revenue model & & & \\
\hline & Role & & & \\
\hline & Strategy & & & \\
\hline & $\begin{array}{l}\text { Logistics task } \\
\text { management }\end{array}$ & & & \\
\hline & $\begin{array}{l}\text { Location } \\
\text { dependence }\end{array}$ & & & \\
\hline & Transparency & & & \\
\hline & $\begin{array}{l}\text { Trust generating } \\
\text { mechanism }\end{array}$ & & & \\
\hline & Cooperation & & & \\
\hline & Marketing & & & \\
\hline & $\begin{array}{l}\text { Geographical } \\
\text { scale }\end{array}$ & & & \\
\hline \multirow[t]{5}{*}{ Crowd } & Character & & & \\
\hline & Transport & & & \\
\hline & Incentive & & & \\
\hline & Motivation & & & \\
\hline & Modal choice & & & \\
\hline
\end{tabular}


by bike when their neighbours are at home [62]. Alternative modes and public transportation should be encouraged [23]. Nevertheless, Rougès and Montreuil [23] also claim that integration of CL delivery requirements in the design of, for example, cars, bicycles and trucks would optimise the process. During the interviews, modal choice received little attention from the practitioners, who considered the demanded logistics service as starting point. Nevertheless, transport modes other than van or car were encouraged when fitting.

\subsection{Sustainability}

Following the SLR and the semi-structured interviews, we determined sustainability implications for each of the defining CL characteristics. To assess the overall sustainability potential of CL, we indicate whether a characteristic affects economy, society and/or environment. Table 4 summarises the findings by highlighting the relevant boxes in grey.

\subsubsection{Economic sustainability}

All characteristics that define a certain CL concept determine the business model and thus impact on its economic sustainability. The $B$ or $C$ distinction for receiver and commissioner steers the platform operations and has an impact on the realisation of other characteristics, including strategies for cooperation and marketing. Platform role and strategy establish where the concept is situated on the axis between community-inspired and business-oriented. Consequently, they have a direct impact on other characteristics such as crowd character and modal choice. Any sustainable business model is dependent on generating sufficient partnerships (cooperation) and users (marketing), in an area that matches the geographical scale on which the CL concept operates.

A sustainable business model depends on well-designed revenue and cost structures [17]. Thanks to the asset-light infrastructure and operational flexibilities of CL, many authors presume a minimisation of costs $[14,21,41]$. This implies that, as opposed to traditional LSPs, no warehouses, vehicle fleet or employed drivers are required [14]. Nevertheless, an appropriate revenue model needs to take account of the additional costs, such as insurance, software development, training, routing instructions, GPS devices and packets for shipments [2]. Designing an effective cost model is a major challenge. It is determined based on crowd characteristics, such as the transport flows, motivation and modal choice [11]. Existing CL platforms employ different strategies to incentivise the crowd. The interviewed practitioners also raised a number of possible applications. Individuals that move dedicatedly or make large detours can be compensated more and monetary, rewarding their flexibility. Vice versa, persuading the crowd to bring along parcels on existing trips could require less earnings or incentives of non-monetary nature. Essentially, addressing the crowd's motivation is paramount. Similar considerations can be made regarding their modal choice. A platform can choose to connect crowd incentives with their chosen vehicle type. For example, more sustainable, more flexible or more spacious vehicles and the costs they bring along (such as fuel costs) can be compensated.

A sustainable concept needs well-preforming service levels. In the case of CL, this translates to timely, guaranteed and efficient execution of logistics tasks. Performance of the system is largely impacted by time flexibility and stop willingness of the crowd [3]. A successful business model therefore requires a large database of individuals, or critical mass, in order to remain competitive during busy times, such as the holiday period $[15,19]$. Involving professional third parties in case of insufficient or underperforming crowd is important from this perspective. Savelsbergh and Van Woensel [17] refer to Walmart, that guarantees same-day delivery to online customers and employs both occasional and company drivers. Third party involvement is tightly linked to the character of the crowd, which can be professional, non-professional or both, but the main difference is the engagement of the individuals executing the logistics tasks. This is done in the traditional way in case of third party involvement and via a marketplace platform in case of the crowd. Service levels also depend on the platform organisation: logistics task management and location-dependence. According to Chen et al. [31], CL can be an economic viable and sustainable option, but it depends on the spatial characteristics of the network and drivers' schedules. A major challenge in this regard is the design of a task-selection that succeeds in minimising time of deliveries while maximising efficiency [9].

Two characteristics balance between economic and social considerations: platform transparency and implemented trust generating mechanisms. Vague or lacking regulatory frameworks concerning sharing economy platforms and CL give rise to important liability questions [2]. Thus, from a business point of view, user trust, safety and security need to be warranted and preserved. However, matters related to social desirability of information sharing and privacy are pressing.

\subsubsection{Social sustainability}

As CL platform users share valuable data (such as their location), privacy is a critical challenge. This has to be handled already in the design stage of the platform creation (trust generating mechanism). Schreieck et al. [40] list seven principles to respect in this regard: proactive not reactive, privacy as the default, privacy embedded into design, full functionality, endto-end security, visibility and transparency and respect for user privacy. In order to protect user data, 'hashing' or transforming personal information is proposed for data analysis that aims to optimise the matching process [40]. They also suggest transparency of data storage and processing to tackle 
privacy questions. The European Commission [47] stimulates CL platforms to comply with the applicable legal framework on the protection of personal data.

De Groen and Maselli [48] claim that the ongoing digital revolution and crowd platforms are slowly changing labour by intermediating work between individuals online, without the intervention of other people or organisations. For the traditional logistics industry, CL can be considered disruptive. As numerous start-ups are creating business models based on low cost structure and power of community, business volume of traditional LSP's can reduce significantly $[23,26]$. Even more, as the crowd only works when demand is sufficient [15], the procedure can be used to replace fixed employees and create costefficiency and savings (third party involvement). This again traces back to the blurring lines between professionals and non-professionals in the logistics industry or the character and incentivisation of the crowd. The opportunity to create a customised working schedule that fits other commitments [23], the ease to convert time and skills into cash [48] and the ability to be in control of amount of work and revenues are key advantages of the system [14]. Some warn for negative side-effects of such flexibility. Although the crowd participates on a voluntary basis, some CL initiatives use a casual workforce of selfemployed drivers and have been criticised for exploitative practices [46]. Platforms limit the freedom of the crowd in order to increase efficiency, for example by allocating tasks to workers that are most available or by attaching rating systems to task acceptance levels. Hence, the platform and platform users are far more dominant in setting the conditions for the crowd than the other way around [48]. De Groen and Maselli [48] summarise that the crowd is exposed to financial insecurities, lacking social protection, isolation and stress, blurring lines between the sphere of work and private life, high competition and uncertainties due to short-term schedules. Underpayment and unfulfilled employment conditions could prove to be an unsustainable business model from a social point of view. While these considerations relate to $\mathrm{CL}$ concepts on the business side of the strategic axis, they are less relevant for community-oriented approaches, which are small-scale and less driven by financial motivation.

Finally, the social impact of the crowd's modal choice concerns the health benefits that result from CL concepts that stimulate soft transportation modes, such as biking and walking. In the Finnish pilot project, several crowd workers that used their bikes, declared to participate in the pilot for the sake of exercise [7]. Moreover, CL initiatives that promote the usage of soft modes instead of trucks, vans and cars trigger health benefits for the entire community.

\subsubsection{Environmental sustainability}

Much of the benefits linked to CL, such as reduction in $\mathrm{CO}_{2}$ emissions, traffic and resource use, are linked to a more efficient usage of loading space. Whether a CL concept works with existing or dedicated trips has an important influence on its environmental impact [21]. The platform's task management and location dependency has the potential to steer this process, as well as the transport behaviour of the crowd itself. It could be argued that trajectory-dependency facilitates the more sustainable use of pre-existing trips while random selection enables additional trips. One interviewee, however, challenged this assumption. Even if a platform focusses on leveraging intended trips, user-friendliness is hindered if tasks are only recommended after executing another task first. The involvement of third parties is per definition relevant in this respect. Professional LSPs make dedicated trips and use in most cases a light-freight vehicle [46]. Nonetheless, traditional LSPs can apply considerable experience and volume in order to guarantee efficient aggregation of parcels. In the CL concept, parcels are processed individually, which might limit the overall positive sustainability impact [23].

The crowd's modal choice is also important from an environmental perspective, which favours soft modes, public transportation and clean vehicles. Trip distance is another influencing factor, which relates to the crowd concepts' geographical scale. Finally, also in the case of environmental impacts of CL is the crowd's main motivation decisive.

To conclude, only three characteristics, third party involvement, crowd motivation and modal choice, impact sustainability as a whole. Four characteristics, logistics task management, location dependence, geographical scale and transport, have an impact on economic and environmental sustainability. Four characteristics, transparency, trust generating mechanism, crowd character and incentives, need to be taken into account for both economic and social concerns. Then, seven characteristics are important from an economic perspective only: receiver and commissioner identity, revenue model, platform role and strategy, cooperation and marketing.

\section{Conclusion}

The goal of this research paper entails to indicate if CL concepts can increase urban transport sustainability, of both passenger and freight flows. By combining desk (systematic literature review of 42 articles) and field research (11 semi-structured interviews), our research concludes with three findings. First, we define $\mathrm{CL}$ as 'an information connectivity enabled marketplace concept 
that matches supply and demand for logistics services with an undefined and external crowd that has free capacity with regards to time and/or space, participates on a voluntary basis and is compensated accordingly'. Second, we list 18 characteristics able to define and describe the broad variety of CL concepts. These characteristics are categorised per involved CL stakeholder-group that they relate to, consisting of receivers that receive the goods, commissioners that send the goods, LSPS that execute transportation in the traditional way, platform providers that match all parties and the crowd. Third, by matching the characteristics with economic, social and environmental sustainability implications, we allow to assess the overall sustainability potential of CL initiatives. All characteristics have an impact on the economic sustainability, given that they are vital business model elements. Only three characteristics affect the three pillars of sustainability: third party involvement, crowd motivation and modal choice.

From a research point of view, the findings complement existing literature by combining both theory and practice to provide information on sharing space for passenger and freight transport in general and the novel topic of CL in particular. From a policy perspective, the research brings evidence that confirms statements of both 'believers' and 'nonbelievers' in the sharing economy, by listing examples of sustainable and less sustainable concepts. We suggest that policymakers explicitly define the characteristics required for $\mathrm{CL}$ initiatives that can be considered for support. Such characteristics can include optimised transport and a non-professional crowd character. The findings prove insightful for practitioners that aim to set up a CL initiative as well, as it provides comprehensive understanding of important concept considerations. A sustainable CL business model provides enhanced service for customers and overall profitability, increases efficiency of vehicle usage and encourages progress in social equity by creating flexible work as opportunity but not as last resort. Overall, the goal of the research is to strengthen insight on CL as an alternative to inefficient UFT flows and to stimulate the efficient usage of the available transportation resources, by addressing relevant stakeholders such as consumers, businesses, policy-makers and researchers. Future research includes a stakeholder-analysis to find out for each of the involved stakeholders what type of CL concept they would support and a sustainability impact assessment of a CL pilot project. This stage of research explicitly involves the crowd, which is a drawback in the current conceptual research endeavour of a concept that is only starting to develop. Other avenues for future research include the potential of CL concepts to scale up and become a credible alternative to traditional logistics services and under which conditions this can take place.

Acknowledgements This work is supported by a research project called 'Crowd Logistics', initiated and funded by VIL (www.vil.be). The authors would like to thank two unknown reviewers for constructive comments to a former version of the paper.

\section{Appendix}

Table 5 List of interviewees

\begin{tabular}{llll}
\hline Date & Type of company & Interviewee's title & Stakeholder \\
\hline $29 / 04 / 2016$ & Parcel express company & $\begin{array}{l}\text { Operations Director } \\
\text { Marketing Manager }\end{array}$ & Platform provider \\
$04 / 05 / 2016$ & Postal operator & Fulfilment Manager & Platform provider \\
$09 / 05 / 2016$ & Third party logistics & Chief Operating Officer & Platform provider \\
& & Distribution Manager & Marketing Manager \\
$11 / 05 / 2016$ & Parcel express company & Operations Director & CSP \\
$18 / 05 / 2016$ & FMCG manufacturer & Supply Network Innovation Manager & Platform provider \\
$19 / 05 / 2016$ & Carrier & Supply Network Innovation Head & Commissioner \\
$20 / 05 / 2016$ & Multi-channel retailer & Head of Online Food Department & Commissioner \\
$20 / 05 / 2016$ & Multi-channel retailer & Head of Online Non-food Department & Platform provider \\
$30 / 05 / 2016$ & Third party logistics & Chief Operating Officer & Platform provider \\
$30 / 05 / 2016$ & Transport software company & Business Development Manager & LSP \\
$06 / 06 / 2016$ & Parcel express company & Groduct Manager & \\
\hline
\end{tabular}


Open Access This article is distributed under the terms of the Creative Commons Attribution 4.0 International License (http:// creativecommons.org/licenses/by/4.0/), which permits unrestricted use, distribution, and reproduction in any medium, provided you give appropriate credit to the original author(s) and the source, provide a link to the Creative Commons license, and indicate if changes were made.

\section{References}

\section{Journal article}

1. Anderson S, Allen J, Browne M (2005) Urban logistics: how can it meet policy makers' sustainability objectives? J Transp Geogr $13: 1$

2. Mladenow A, Bauer C, Strauss C (2016) 'crowd logistics': the contribution of social crowds in logistics activities. Int J Web Inform Syst 12:3

3. Arslan A, Agatz N, Kroon L, Zuidwijk R (2016) Crowdsourced delivery: a dynamic pickup and delivery problem with ad-hoc drivers. SSRN electronic journal:1-29. doi:10.2139/ssrn. 2726731

4. Wang Y, Zhang D, Liu Q, Shen F, Lee LH (2016) Towards enhancing the last-mile delivery: an effective crowd-tasking model with scalable solutions. Transport Res E-Log 93:279-293. doi:10.1016/ j.tre.2016.06.002

5. Dörrzapf L, Berger M, Breitfuss G, Remele E (2016) Crowd Delivery Als Neues Lieferkonzept Zur Stärkung Des „Lokalen Marktplatzes“. REAL CORP 2016 Proceedings, 197-206

6. Chen C, Pan S, Wang Z, Zhong RY (2016) Using taxis to collect citywide E-commerce reverse flows: a crowdsourcing solution. Int J Prod Res:1-12. doi:10.1080/00207543.2016.1173258

7. Paloheimo H, Lettenmeier M, Waris H (2015) Transport reduction by crowdsourced deliveries - a library case in Finland. J clean prod: 1-12. doi:10.1016/j.jclepro.2015.04.103

8. Crainic TG, Montreuil B (2016) Physical internet enabled Hyperconnected City logistics. Transport Res Procedia 12:383398. doi:10.1016/j.trpro.2016.02.074

9. Mcinerney J, Rogers A, Jennings NR (2013) Bus, bike and random journeys: crowdsourcing aid distribution in Ivory Coast. Significance 10(4):4-9. doi:10.1111/j.1740-9713.2013.00673

10. Cohen B, Muñoz P (2015) Sharing cities and sustainable consumption and production: towards an integrated framework. J clean prod: 1-11. doi:10.1016/j.jclepro.2015.07.133

11. Archetti C, Savelsbergh M, Speranza G (2016) The vehicle routing problem with occasional drivers. Eur J Oper Res 254(2):472-480

12. Macharis C, Kin B (2017) The 4 A's of Sustainable City distribution: innovative solutions and challenges ahead. Int J Sustain Transp 11(2):59-71. doi:10.1080/15568318.2016.1196404

13. Zito P, Salvo G (2011) Toward an urban transport sustainability index: an European comparison. Eur Transport Res Rev 3(4):179-195

14. Botsman R (2014) Crowdshipping: using the crowd to transform delivery. AFR Boss Magazine

15. Hodson H (2013) You've Got Chain Mail. New Sci 218:17-18. doi: 10.1016/S0262-4079(13)61234-8

16. Erickson LB, Trauth EM (2013) Getting work done: evaluating the potential of crowdsourcing as a model for business process outsourcing service delivery. Annual Computers and People Research Conference:135-140. doi:10.1145/2487294.2487323

17. Savelsbergh M, Van Woensel T (2016) City logistics: challenges and opportunities. Transp Sci 50(2):579-590

18. Thaker R (2015) Crowdsourcing: a survey. Int J Eng Res Appl 5(7): 73-81
19. Insel N (2013) A soon and distant Christmas. It's All in the Delivery Nature 504:476-476

20. Guo B, Chen C, Yu Z, Zhang D, Zhou X (2015) Building humanmachine intelligence in mobile crowd sensing. IT Professional doi: 10.1109/MITP.2015.50

21. Qi W, Li L, Liu S, Shen ZM (2016) Shared Mobility for Last-Mile Delivery: Design, Operational Prescriptions and Environmental Impact. Manuf Serv Op 1-42

22. Hübner A, Kuhn H, Wollenburg J (2016) Last mile fulfilment and distribution in Omni-Channel grocery retailing - a strategic planning framework. Int J Retail Distrib Manag 44(3):228-247. doi:10. $1108 / 09564230910978511$

\section{Conference paper}

23. Rougès J, Montreuil B (2014) Crowdsourcing delivery: new interconnected business models to reinvent delivery. 1st international physical internet conference, Quebec City, Canada

24. Mehmann J, Frehe V, Teuteberg F (2015) Crowd logistics - a literature review and maturity model. Proceedings of the Hamburg international conference of logistics. Hamburg, Germany

25. Mckinnon A (2015) City logistics innovations: game-changers or over-hyped curiosities. TRB Executive Committee, Washington DC, USA

26. Carbone V, Rouquet A, Roussat C (2015) 'carried away by the crowd': what types of logistics characterise collaborative consumption? Conference: 1 st international workshop on sharing economy, Utrecht, the Netherlands

27. Harald K, Graf H, Hoertenhuber S, Widmann R, Stadlmann B (2016) SmartBox - an Austrian PI solution leading to small loads mobility 4.0. 3rd international physical internet conference, Atlanta, USA

28. Taylor J (2015) Crowdsourcing IT Work: A Three-Fold Perspective from the Workers, Buyers, and Platform Providers. 2015 ACM SIGMIS conference on computers and people research, Newport Beach, USA

29. Chen C, Cheng S, Gunawan A, Misra A, Dasgupta K, Chander D (2014) TRACCS: a framework for trajectory-aware coordinated urban crowd-sourcing. Second AAAI conference on human computation and crowdsourcing. Pittsburgh, USA

30. Slabinac M (2015) Innovative solutions for a 'last-mile' delivery - a European experience. 15th international scientific conference business logistics in modern management, Osijek, Croatia

\section{Working paper}

31. Chen W, Mes M, Schutten M (2016) Multi-hop driver-parcel matching problem with time windows. WP 507, Beta working paper series 507. doi:10.13140/RG.2.1.1804.8402

32. Kung L, Zhong G (2016) Platform delivery: a game-theoretic analysis of a new delivery model in the sharing economy. Taipei, Taiwan

\section{Book}

33. Verlinde $\mathrm{S}$ (2015) Promising but challenging urban freight transport solutions: freight flow consolidation and off-hour deliveries. Vrije Universiteit Brussel

34. Soubbotina TP (2004) Beyond economic growth: an introduction to sustainable development, Second edn. World Bank, Washington, DC

35. Gudmundsson H, Hall RP, Marsden G, Zietsman J (2016) Sustainable transportation. Indicators, frameworks, and performance management. Springer Verlag, Heidelberg

36. Fink A (2013) Conducting research literature reviews: from the internet to paper. SAGE Publications, London 


\section{Book chapter}

37. Allen J, Browne M, Holguín-veras J (2015) Sustainability strategies for city logistics. In: Mckinnon a, Browne M, Whiteing a, Piecyk M (eds) green logistics ( $3^{\text {rd }}$ edition). Kogan page, pp 293-319

38. Mckinnon A, Bilski B (2015) Innovations in global logistics. In: Bilski B, Verkerk M (eds) Murray D. Breakthrough, From Innovation to Impact. The Owls Foundation, pp 19-38

39. Martins TCM, de Souza Bermejo PH, de Souza Villas Boas W (2015) Open innovation for citizen coproduction. In: Andersen KN, Francesconi E, Grönlund A, van Engers TM (eds) Electronic government and the information systems perspective. Springer Verlag, Heidelberg, pp 15-25

40. Schreieck M, Pflügler C, Dehner C, Vaidya S, Bönisch S, Wiesche M, Krcmar H (2016) A concept of crowdsourced delivery for small local shops. In: Mayr HC, Fellner D, Flegel U, Frank U, Freytag J, Goedicke M, Hofestädt R, Koch M, Lehmann A, Mayr EW, Schubert S, Timm I, Vosseberg K, Wimmer M (eds) Lecture notes in informatics (LNI). Gesellschaft für Informatik, Bonn, pp 375384

\section{Report}

41. Durand A, Lavigne-Lefebvre N, Rougès J, Carrier M, Gagné C, Mercier J, Montreuil B (2014) L'électrification Des Transports: Une Perspective Québécoise. Université Laval, Rapport du groupe de travail

42. Vaughan R, Daverio R (2016) Assessing the size and presence of the collaborative economy in Europe. PwC UK

43. European Commission (2016) Flash Eurobarometer 438 - march 2016, the use of collaborative platforms. European Union, Report

44. Brundtland GH (1987) Our common future: the world commission on environment and development. England, Oxford

45. Demary V, Engels B (2016) Collaborative business models and efficiency - potential efficiency gains in the European Union. Cologne Institute for Economic Research, impulse paper no. 07

46. Mckinnon A (2016) Crowdshipping - a communal approach to reducing urban traffic levels? Kuehne logistics university, logistics white paper $1 / 2016$

47. European Commission (2016) A European Agenda for the Collaborative Economy, \{SWD(2016) 184 final $\}$

48. De Groen WP, Maselli I (2016) The impact of the collaborative economy on the labour market. Centre for European Policy Studies, special report

\section{Online document}

49. European Environment Agency (2016) Occupancy rates of passenger vehicles. European Environment Agency. http://www.eea. europa.eu/data-and-maps/indicators/occupancy-rates-of-passengervehicles/occupancy-rates-of-passenger-vehicles. Accessed 26 Sept 2016

50. Postmates (2016) Postmates on-demand delivery. Postmates. https://postmates.com/. Accessed 26 Sept 2016

51. UberRush (2016) Deliver with Uber earn on your own schedule. UberRush. https://www.uber.com/signup/drive/deliver/. Accessed 26 Sept 2016

52. UberRush (2016) UberRUSH delivers faster than you can imagine for less than You'll believe. UberRUSH. https://rush.uber.com/ how-it-works. Accessed 26 Sept 2016

53. den Bakker F (2013) DHL Laat Consumenten Zelf Pakketten Bezorgen. Logistiek.nl. http://www.logistiek.nl/distributie/nieuws/ 2013/9/dhl-laat-consumenten-zelf-pakketten-bezorgen-10146245. Accessed 4 Sept 2016

54. Byl R (2016) Bpost Lanceert Bringr: Op Uber Geïnspireerde App Om Pakjes Te Bezorgen. Trends.be. http://trends.knack.be/ economie/bedrijven/bpost-lanceert-bringr-op-uber-geinspireerdeapp-om-pakjes-te-bezorgen/article-normal-717843.html. Accessed 20 June 2016

55. Nassauer S (2016) Wal-Mart to test grocery delivery with Uber and Lyft. Service set to be available later this month in Denver and Phoenix. The Wall Street Journal. https://www.wsj.com/articles/ wal-mart-to-test-grocery-delivery-with-uber-and-lyft-1464926454. Accessed 3 June 2016

56. Stil H (2016) Webwinkel Zalando Groeit Als Kool. De Ondernemer. https://www.deondernemer.nl/nieuwsbericht/ 141652/webwinkel-zalando-groeit-als-kool. Accessed 23 Dec 2016

57. Trunkrs (2016) Over Ons. Trunkrs. https://trunkrs.nl/contact/overons/. Accessed 26 Sept 2016

58. Instacart (2016) Become a shopper. Instacart. https://shoppers. instacart.com/. Accessed 26 Sept 2016

59. Bringbee (2014) BringBee Stellt Betrieb Ein. Startupticker. http:// www.startupticker.ch/en/news/october-2014/bringbee-stelltbetrieb-ein. Accessed 26 Sept 2016

60. Sjipit (2016) The market place for shipping stuff. Sjipit. http://www. sjipit.nl/en. Accessed 26 Sept 2016

61. Baert D (2016) Amper 10 Procent Belasting Voor Wie Bijverdient via Uber En Co. Deredactie.be. http://deredactie.be/cm/vrtnieuws/ economie/1.2653689. Accessed 26 Sept 2016

62. Koiki (2016) The green delivery service by people from your Neighbourhood. Koiki. http://www.koiki.eu/en/. Accessed 26 Sept 2016 